\title{
Identificación de envases vacíos de plaguicidas en plantaciones de nopal verdura, Opuntia ficus-indica (L.) Mill. (Cactaceae), en Morelos, México
}

\author{
Empty pesticide containers in prickly pear cactus, Opuntia ficus-indica (L.) Mill. (Cactaceae), \\ from Morelos state, Mexico
}
Irene Iliana Ramírez-Bustos ${ }^{1}$, Víctor López-Martínez ${ }^{1 *}$, Porfirio Juárez-López ${ }^{1}$, Dagoberto Guillén- Sánchez ${ }^{1}$, Irán Alia-Tejacal ${ }^{1}$, Ismael Rivera-León ${ }^{2}$, Hugo Albeiro Saldarriaga-Noreña ${ }^{2}$, Daniel Jiménez-García ${ }^{3}$

\begin{abstract}
RESUMEN
Los envases de plaguicidas vacíos desechados inadecuadamente representan un peligro de contaminación química en la producción de alimentos. Con la finalidad de determinar si los envases de plaguicidas son manejados de manera inapropiada en la región productora de nopal verdura, Opuntia ficus-indica (L.) Mill. (Cactaceae), en Morelos, México, se realizaron recorridos en los municipios de Tepoztlán, Tlalnepantla, Tlayacapan y Totolapan, para colectar, identificar, contabilizar y clasificar envases. Se encontró la presencia de 729 envases en 227 puntos de muestreo con incidencia mayor en Tlalnepantla. Los envases se clasificaron como insecticidas, insecticidas/acaricidas, herbicidas, fungicidas y bactericidas. Se identificaron plaguicidas altamente peligrosos, extremadamente peligrosos (organofosforados) y con prohibición de uso a nivel mundial (metamidofós, monocrotofós). Ninguno de los insumos fitosanitarios encontrados contó con autorización oficial para uso en el cultivo. En la producción de nopal verdura de Morelos, no se realiza el desecho adecuado de envases de plaguicidas, lo que representa peligro de contaminación química al trabajador agrícola, al consumidor final y al medio ambiente.
\end{abstract}

PALABRAS CLAVE

inocuidad, reducción de riesgos, organofosforados, organoclorados, glifosato

\begin{abstract}
Inadequately discarded empty pesticide containers represents a chemical contamination risk in vegetable food production. In order to determine if empty pesticide containers are incorrectly manipulated in the prickly pear cactus [Opuntia ficus-indica (L.) Mill., Cactaceae) production region from Morelos, Mexico, surveys were conducted in the municipalities of Tepoztlan, Tlalnepantla, Tlayacapan, and Totolapan. 729 empty pesticide containers in 227 sampling points were detected, major incidence occurred in Tlalnepantla; and were classified as insecticides, insecticies/acaricides, herbicides, fungicides, and bactericides. Highly and extremely dangerous (organophosphorates), and banned worldwide (metamidophos, monocrotophos) were observed. All phytosanitary supplies determined in this study are not officially accepted for its use in prickly pear cactus crop. In local prickly pear cactus commercial area, pesticides containers are not officially improperly discarded, increasing chemical contamination risk for agricultural workers, final consumers, and environment.
\end{abstract}

KEYWORDS

Food safety, risks reduction, organophosphates, organochlorines, glifosate

\footnotetext{
${ }^{1}$ Posgrado en Ciencias Agropecuarias y Desarrollo Rural, Facultad de Ciencias Agropecuarias, Universidad Autónoma del Estado de Morelos. México.

${ }^{2}$ Centro de Investigaciones Químicas, Instituto de Ciencias Básicas y Aplicadas, Universidad Autónoma del Estado de Morelos. México.

${ }^{3}$ Centro de Agroecología y Ambiente, Instituto de Ciencias, Benemérita Universidad Autónoma de Puebla. México.

*Autor para correspondencia. Av. Universidad 1001, col. Chamilpa. 62209 Cuernavaca, Morelos, México.

Correo electrónico: victor.lopez@uaem.mx
}

Recibido: 10 de enero de 2018

Aceptado: 28 de abril de 2018 


\section{INTRODUCCIÓN}

El nopal verdura, Opuntia ficus-indica (L.) Mill. (Cactaceae), es uno de los principales elementos de la dieta del consumidor mexicano con alto valor nutritivo (Stintzing y Carle 2005). En 2016, se cultivaron 12,620.4 ha en 26 estados de la República Mexicana, con un volumen de 810,938.99 t (SIAP 2018). El 30.94 $\%$ de la superficie cultivada nacional (3,905 ha) y el $45.35 \%(367,826 \mathrm{t})$ del volumen total se producen en cuatro municipios del estado de Morelos (Tepoztlán, Tlalnepantla, Tlayacapan y Totolapan) (SIAP 2018).

En este cultivo, el uso de plaguicidas sintéticos es la técnica más empleada para el control de poblaciones de insectos plaga (Aldana et al. 2008; Cerón-González et al. 2012); muchos de éstos representan efectividad alta para el control de plagas (Cano y Mendoza 2017). El uso inapropiado de estos insumos representa la posibilidad de presencia de residuos en el cultivo (Aldana et al. 2008; Angeles-Núñez et al. 2014), lo que provoca altos costos económicos, contaminación ambiental, disminución de organismos benéficos y especies silvestres, intoxicaciones, efectos negativos sobre aplicadores y personas relacionadas con el manejo de plaguicidas (Gutiérrez-Ramírez et al. 2013).

El buen uso y manejo seguro de plaguicidas en México recomienda la eliminación apropiada de los envases de insumos fitosanitarios, con la responsabilidad compartida de los integrantes en la producción (FAO 2008) en los procedimientos recomendados: selección de productos autorizados y vigentes; transporte y almacenamiento adecuados; calibración de equipos de aspersión, manejo de caldos sobrantes, y manejo adecuado de envases vacíos son los más importantes (O'Connor 2000). Debe considerarse que un envase vacío nunca podrá limpiarse por completo, por lo que debe eliminarse mediante procedimientos que garanticen su inutilización ya que los residuos presentes en el contenedor son fuente potencial de contaminación (FAO 2006).

Por lo anteriormente expuesto, el objetivo del presente trabajo fue documentar la presencia de envases de insumos fitosanitarios en la región productora de nopal verdura en Morelos, México, con la finalidad de identificar, contabilizar y clasificar los envases, en relación con los peligros que representan para la salud del trabajador agrícola, el consumidor y el medio ambiente.

\section{Materiales Y MÉtodos}

\section{Lugar de estudio}

Se realizaron recorridos de enero a diciembre de 2016, en zonas de producción de nopal verdura en los municipios de Tepoztlán, Tlalnepantla, Tlayacapan y Totolapan, estos se encuentran ubicados al noroeste y centro del estado de Morelos; cuentan con un clima templado-subhúmedo con una temperatura promedio de $16^{\circ} \mathrm{C}$ y precipitación pluvial promedio de 913 milímetros al año (INAFED 2010). Las parcelas fueron seleccionadas al azar y se visitaron una vez durante el período de muestreo.

Durante los recorridos se inspeccionaron visualmente las parcelas cada tres surcos hasta finalizar la plantación. Se geoposicionó el punto de colecta para su identificación por cada envase o grupo de envases encontrados con un sistema de posicionamiento global Mapsource ${ }^{\circledast}$ Cartography (Garmin ${ }^{\circledR}$, Olathe, USA). Los envases detectados se manipularon con equipo de protección (guantes de plástico, mascarilla con filtros de carbón activado y lentes de protección), almacenados temporalmente en bolsas trasparentes de plástico $(1.0 \times 0.50 \mathrm{~m}) \mathrm{y}$ transportados al centro de acopio temporal, ubicado en la localidad de Xalostoc, Municipio de Ayala, Estado de Morelos. Se documentó la existencia de envases con fotografía mediante cámara digital (Sony ${ }^{\circledR}$, Cyber shot, modelo W320) y se clasificaron de acuerdo con el grupo de plaguicidas al que pertenecían.

\section{Clasificación de agroquímicos}

La clasificación se realizó a partir de la información presente en la etiqueta del envase de acuerdo al modo de acción, grupo químico, ingrediente activo, nombre comercial, clasificación toxicológica y vigencia. Para insecticidas, se consideró lo propuesto por Sparks y Nauen (2015); para herbicidas, lo indicado por el comité de resistencia a herbicidas, y para fungicidas, lo señalado por el comité de resistencia a fungicidas, consultado en la página de la Fungicide Resistance Action Committee (FRAC 2017). La clasificación por categoría toxicológica y vigencia de los agroquímicos se basó en lo propuesto por la Organización Mundial de la Salud (WHO 2010). Se consultaron los registros sanitarios de los insumos, autorizados por la Comisión Federal para la Protección contra Riesgos Sanitarios (COFEPRIS 2017). 


\section{Resultados y discusión}

Distribución de envases. Se ubicaron 227 puntos en la zona de estudio con un total de 729 envases, considerando la superficie por municipio: Tlalnepantla (2,802 ha), Totolapan (548 ha), Tlayacapan (505 ha) y Tepoztlán (50 ha) (SIAP 2018). Coincide de mayor a menor el número de envases encontrados y puntos de colecta realizados (cuadro 1), por lo que podemos inferir que éste dependió de la superficie en producción del cultivo. Productores con conocimientos o capacitación reducida en el buen uso y manejo de agroquímicos, no eliminan de manera apropiada los contenedores vacíos, sino que los depositan dentro de la unidad de producción, los queman o los arrojan a canales de riego o cuerpos de agua (Montoro et al. 2009). La presencia de envases de plaguicidas abandonados en las parcelas de cultivo es resultado de la suma de diversos factores, como falta de capacitación y espacios para almacenamiento temporal definitivo de envases. En la región de producción de nopal verdura sólo se encuentran cuatro centros de acopio temporales (comúnmente llamados "jaulas"), ubicados en Tlalnepantla, de donde se transportan a un punto para disposición final, ubicado en la localidad de Xalostoc, municipio de Ayala (observación en campo). Posiblemente, el incremento y distribución adecuada de estos centros de acopio facilitará a mediano y largo plazo, la correcta eliminación de los envases.

Cuadro 1. Distribución de envases de plaguicidas encontrados en la zona de producción de nopal verdura en Morelos, México.

\begin{tabular}{lcc}
\hline MunicipIo & $\begin{array}{c}\text { NÚM. DE } \\
\text { ENVASES }\end{array}$ & $\begin{array}{c}\text { NÚM. DE } \\
\text { PUNTOS DE } \\
\text { COLECTA }\end{array}$ \\
\hline Tepoztlán & 17 & 4 \\
Tlalnepantla & 429 & 133 \\
Tlayacapan & 258 & 80 \\
Totolapan & 25 & 10 \\
\hline
\end{tabular}

Insecticidas. Fueron de mayor presencia envases de organofosforados (131), en comparación con organoclorados (40), carbamatos (36) y piretroides (31), aunque la diversidad de ingredientes activos fue igual entre organoclorados y organofosforados, por lo que ocho ingredientes activos concentraron $72.08 \%$ de envases de esta categoría (cuadro 2). Debido al espectro de distribución y difícil biodegradación de este grupo, los organoclorados representan una seria amenaza, puesto que constituyen compuestos altamente tóxicos, que inducen mutagénesis (alteración del ADN o de los cromosomas); teratogénesis (malformaciones en el embrión) y alteraciones sobre una gran variedad de funciones metabólicas y de reproducción (Goldberg,1995). Los efectos en humanos pueden ser perinatales, ya que estos productos pueden atravesar la barrera placentaria (Zaragoza-Bastida et al. 2016). Sus propiedades fisicoquímicas los hacen muy resistentes a la degradación biológica, por lo que son altamente persistentes (Iwata et al. 1994).

El uso de insecticidas con categoría I, reconocidos por el color rojo en la etiqueta y considerados extremadamente peligrosos, representaron $15.77 \%$ de los envases detectados; 64 envases fueron de metamidofós y monocrotofós, ingredientes activos prohibidos para su uso por la Convención de Rotterdam (FAO 2015) y representan un peligro de toxicidad aguda, por lo que se debe impulsar su prohibición total en la agricultura regional.

Por su parte, $72.7 \%$ de los productos encontrados pertenecen a plaguicidas considerados altamente peligrosos (PAN 2016). La necesidad de emplear esta cantidad y variedad de insecticidas obedece principalmente a la diversidad de insectos plaga y a la falta de alternativas de manejo: más de diez insectos son considerados como plaga en nopal verdura en México (Badii y Flores 2001; De Jesús et al. 2016; Reyes-Pérez et al. 2013; Vargas et al. 2008).

El picudo del nopal, Cactophagus spinolae (Gyllenhal) (Coleoptera: Curculionidae), es una de las plagas más importantes en el país (López-Martínez et al. 2016), con daño grave infringido por larvas y adultos (Cerón-González et al. 2012); los hábitos crípticos de esta larva condicionan la aplicación continua de insecticidas contra la fase adulta. Otra plaga secundaria que obliga a la aplicación regular de agroquímicos es la cochinilla silvestre, Dactylopius opuntiae (Cockerell) (Hemiptera: Coccidae), que en el país afecta a 17 especies cultivadas y silvestres (Chávez-Moreno et al. 2011); la alimentación causa clorosis en cladodios y frutos y en altas densidades mata a la planta infestada (Vanegas-Rico et al. 2010).

Insecticidas/acaricidas. Este grupo fue representado por 199 envases, tres grupos toxicológicos y un producto que combina dos ingredientes activos de dos grupos toxicológicos (clorpirifós etil + permetrina). En este grupo de envases se observó mayor diversidad de ingredientes activos (14) y nombres comerciales 
Cuadro 2. Clasificación de envases de insecticidas abandonados en parcelas de nopal verdura en Morelos, México.

\begin{tabular}{|c|c|c|c|c|}
\hline Grupo químico & $\begin{array}{l}\text { INGREDIENTE } \\
\text { ACTIVO }\end{array}$ & $\begin{array}{l}\text { NúM. DE } \\
\text { ENVASES }\end{array}$ & NOMbre COMERCIAL & $\begin{array}{l}\text { CLASIFICACIÓN } \\
\text { TOXICOLÓGICA }\end{array}$ \\
\hline \multirow[t]{2}{*}{ Carbamatos } & Metomilo $^{1}$ & 28 & Lanate $^{\circledR}$ & II \\
\hline & Oxamil $^{1}$ & 8 & Vydate $\mathrm{L}^{\circledR} \mathrm{CE}$ & II \\
\hline \multirow[t]{2}{*}{ Organoclorados } & Dicofol & 4 & $\mathrm{AK}-20^{\circledR}$ & IV \\
\hline & Dimetoato $^{1}$ & 10 & Micuate $^{\circledR} 600$ & III \\
\hline \multirow[t]{6}{*}{ Organofosforados } & Clorpirifós etil $^{1}$ & 12 & Libero $^{\circledR} 480$ & III \\
\hline & Diclorvós $^{1}$ & 14 & Luzaphos $^{\circledR} 50$ & II \\
\hline & Metamidofós ${ }^{2}$ & 22 & Mataqu $^{\circledR} 600$ & I \\
\hline & Metidatión ${ }^{1}$ & 51 & Suprathion ${ }^{\circledR} 40 \mathrm{CE}$ & I \\
\hline & Monocrotofós ${ }^{2}$ & 42 & $\begin{array}{c}\text { Monocron }^{\circledR} 600 \text {, Monocrotofos }^{\circledR} 600, \\
\text { Monoupe }^{\circledR} 60 \% \text { SL }\end{array}$ & I \\
\hline & Ometoato $^{1}$ & 16 & Vanucron $^{\circledR} 600$, Velcron $^{\circledR} 60$, Folimat $^{\circledR}$ & II \\
\hline Piretroides & Permetrina $^{1}$ & 31 & Matagus $^{\circledR} 34$ & III \\
\hline
\end{tabular}

${ }^{1}$ Productos considerados altamente peligrosos (PAN, 2016).

${ }^{2}$ Ingredientes activos sujetos a la Convención de Rotterdam debido a que están prohibidos o están severamente restringidos (FAO, 2015).

(28) con respecto al grupo de insecticidas. De los ingredientes activos aquí reportados, sólo uno (cipermetrina) no es considerado altamente peligroso (FAO 2015); 94.97\% de los ingredientes restantes está prohibido a nivel internacional o es clasificado como altamente peligroso (cuadro 3). El uso de productos con efecto insecticida y acaricida, puede deberse a la necesidad de combatir problemas por ácaros fitófagos en la producción, además de que al mismo tiempo se pretenda controlar otras plagas insectiles. Tetranychus merganser Boudreaux (Acari: Tetranychidae) es un ácaro que afecta cladodios tiernos (5-7 $\mathrm{cm}$ de longitud) al alimentarse, y provoca lesiones en forma de círculos blancos en la superficie del cladodio, lo que afecta la calidad comercial del producto (Lomeli-Flores et al. 2008). En México, T. merganser tiene desarrollo óptimo entre los 23 y $27{ }^{\circ} \mathrm{C}$ (Reyes-Pérez et al. 2013) y el daño más grave ocurre en temporada de sequía, principalmente de febrero a abril (Lomeli-Flores et al. 2008). Proteger la sanidad de los cladodios inmaduros se reflejará en la calidad y precio en cosecha, así que la infestación por este ácaro y el control en poblaciones iniciales obligan al productor a la aplicación de estos productos.

Herbicidas. El tercer grupo en importancia por el número de envases encontrados fue el de herbicidas: 142 envases fueron clasificados en cuatro grupos químicos, más un producto que incluye dos ingredientes activos de dos grupos químicos distintos (cuadro 4). El 58.10\% de los envases perteneció a glifosato pero, en combinación con carfentrazone etil, fue encontrado en 16 envases. Glifosato es un herbicida de amplio espectro y afecta malezas de hoja ancha y angosta (Cox 1998), de ahí que sea atractivo para los productores usarlo; sin embargo, este ingrediente activo es considerado como altamente peligroso para su uso en la agricultura (PAN 2016), al igual que otros tres de los ingredientes activos de herbicidas detectados (cuadro 4). Se ha considerado que un uso excesivo de glifosato en el cultivo de nopal verdura en Morelos representa riesgos de efectos de resistencia, intoxicación y residualidad en el producto cosechado (Aguilar-Carpio et al. 2016).

Fungicidas. El uso de fungicidas en el cultivo de nopal verdura es menor en comparación con insecticidas, ya que sólo se encontraron 81 envases, con cinco grupos químicos, seis ingredientes activos y clasificación toxicológica cuatro (cuadro 5). La mancha negra Pseudocercospora opuntiae Ayala-Escobar, Braun \& Crous (Ayala-Escobar et al. 2006) es una enfermedad fungosa que afecta a plantaciones ubicadas en las regiones con mayor altitud en Morelos; llega a causar la pérdida total cuando existe mal manejo de la enfermedad (Quezada-Salinas et al. 2006). El descubrimiento e identificación del patógeno causante de la sintomatología es reciente (Ayala-Escobar et al. 2006) y quizá no haya permeado entre productores la opción más adecuada de manejo. De los ingredientes activos 
Cuadro 3. Clasificación de envases de insecticidas/acaricidas abandonados en parcelas de nopal verdura en Morelos, México.

\begin{tabular}{|c|c|c|c|c|}
\hline GruPo QUímICo & $\begin{array}{l}\text { INGREDIENTE } \\
\text { ACTIVO }\end{array}$ & $\begin{array}{l}\text { NÚM. DE } \\
\text { ENVASES }\end{array}$ & NOMbre COMERCIAL & $\begin{array}{l}\text { CLASIFICACIÓN } \\
\text { TOXICOLÓGICA }\end{array}$ \\
\hline Avermectinas & Abamectina $^{1}$ & 10 & Minatrin ${ }^{\circledR}$ & NA \\
\hline \multirow[t]{2}{*}{ Carbamatos } & Carbofurán ${ }^{1}$ & 10 & Furadan ${ }^{\circledR} 5 \mathrm{G}$ & III \\
\hline & Metomilo $^{1}$ & 15 & Kuik $^{\circledR} 90$ PS & II \\
\hline \multirow[t]{7}{*}{ Organofosforados } & Acefate $^{1}$ & 30 & Unifate $^{\circledR}$, Ultra $^{\circledR} 97$ DF & IV \\
\hline & Clorpirifós etil $^{1}$ & 19 & $\begin{array}{c}\text { Carioca }^{\circledR} 48 \text { CE, Clorver }{ }^{\circledR} 480, \text { Gard }^{\circledR} 480, \\
\text { Lorsban }^{\circledR} 480 \text { Em, Ventax } \\
\text { Co }^{\circledR} 480 \text { CE }\end{array}$ & III \\
\hline & Diazión ${ }^{1}$ & 18 & Diazinon Dragon ${ }^{\circledR} 25 \mathrm{E}$ & IV \\
\hline & Dimetoato $^{1}$ & 12 & $\begin{array}{c}\text { Danadim Progress }{ }^{\circledR} 400 \text { CE, Dimetoato }{ }^{\circledR} \\
400 \text { CE, Dimetri }{ }^{\circledR} 400, \text { Perfekthion }{ }^{\circledR}, \\
\text { Scudetto }^{\circledR}, \text { Tridente }^{\circledR}\end{array}$ & III \\
\hline & Malatión ${ }^{1}$ & 10 & Malathion $1000 \mathrm{E}$ & IV \\
\hline & Monocrotofós² & 12 & $\begin{array}{c}\text { Monocotrofos }{ }^{\circledR} 600, \text { Monocron } \\
\text { Vanucron }^{\circledR} 600 \text { LM, } \\
\text { Velcron }^{\circledR} 60\end{array}$ & II \\
\hline & $\begin{array}{l}\text { Oxidimetón } \\
\text { metil }^{1}\end{array}$ & 10 & Metasystox ${ }^{\circledR} \mathrm{R} 25$ & III \\
\hline $\begin{array}{l}\text { Organofosforados }+ \\
\text { Piretroides }\end{array}$ & $\begin{array}{l}\text { Clorpirifós etil + } \\
\text { permetrina }^{1}\end{array}$ & 12 & Disparo $^{\circledR}$, Flash Ultra ${ }^{\circledR}$, Foley Rey ${ }^{\circledR}$ & III \\
\hline \multirow[t]{2}{*}{ Piretroides } & Cipermetrina & 10 & Arrivo $^{\circledR} 200 \mathrm{CE}$, Siroco $^{\circledR} 20$ Diablo & IV \\
\hline & Permetrina $^{1}$ & 12 & & III \\
\hline
\end{tabular}

${ }^{1}$ Productos considerados altamente peligrosos (PAN, 2016).

${ }^{2}$ Ingredientes activos sujetos a la Convención de Rotterdam debido a que están prohibidos o están severamente restringidos (FAO, 2015).

Cuadro 4. Clasificación de envases de herbicidas abandonados en parcelas de nopal verdura en Morelos, México.

\begin{tabular}{|c|c|c|c|c|}
\hline GRUPO QUíMICo & $\begin{array}{l}\text { INGREDIENTE } \\
\text { ACTIVO }\end{array}$ & $\begin{array}{l}\text { NÚM. DE } \\
\text { ENVASES }\end{array}$ & NOMbRe COMERCIAL & $\begin{array}{l}\text { ClasificaCión } \\
\text { TOXICOLÓGICA }\end{array}$ \\
\hline Fenóxidos & $2,4-\mathrm{D}^{1}$ & 18 & $\begin{array}{c}\text { Amina } 4 \text { Diablo }^{\circledR} \text {, Desmonte }{ }^{\circledR} 4 \mathrm{~EB}, \\
\text { Esteron }^{\circledR} 47-\mathrm{M}\end{array}$ & III \\
\hline Bipiridilos & Paraquat $^{1}$ & 7 & Lucaquat ${ }^{\circledR} 25 \%$ S.A. & III \\
\hline Glicinas & Glifosato $^{1}$ & 96 & 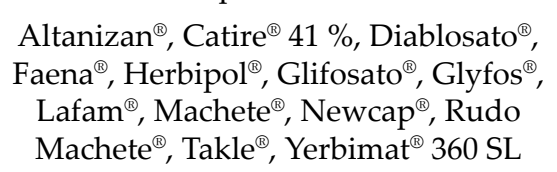 & III \\
\hline Triazinas & Atrazina $^{1}$ & 17 & $\begin{array}{c}\text { Atraplex® 90, Gesaprim Calibre }{ }^{\circledR} 90 \\
\text { GDA, Itertrazina }{ }^{\circledR}\end{array}$ & \\
\hline Triazolinona/Glicina & 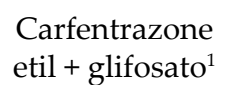 & 19 & Candela Super ${ }^{\circledR}$ & IV \\
\hline
\end{tabular}

${ }^{1}$ Productos considerados altamente peligrosos (PAN, 2016).

de fungicidas identificados, $100 \%$ es considerado altamente peligroso (PAN 2016), por lo que deberá impulsarse el uso de alternativas a estos fungicidas (Hernández-Sánchez et al. 2014).
Bactericidas. Ésta fue una categoría escasamente representada: se encontraron tres envases con grupo químico tetraciclina, ingrediente activo clorhidrato de oxitetraciclina, clasificación toxicológica 4 , y dos nombres comerciales (Livamicina agrícola ${ }^{\circledR}$ y Terra ${ }^{\circledR}$ $5 \% \mathrm{CU})$. En el país, se ha registrado la presencia 
Cuadro 5. Clasificación de envases de fungicidas abandonados en parcelas de nopal verdura en Morelos, México.

\begin{tabular}{|c|c|c|c|c|}
\hline Grupo Químico & $\begin{array}{l}\text { INGREDIENTE } \\
\text { ACTIVO }\end{array}$ & $\begin{array}{l}\text { NÚM. DE } \\
\text { ENVASES }\end{array}$ & NOMbre COMERCial & $\begin{array}{l}\text { CLASIFICACIÓN } \\
\text { TOXICOLÓGICA }\end{array}$ \\
\hline Benzimidasoles & Benomilo $^{1}$ & 16 & Promyl $^{\circledR} 50 \mathrm{PH}$ & IV \\
\hline Inórganico & $\begin{array}{l}\text { Oxicloruro de } \\
\text { cobre }\end{array}$ & 24 & $\mathrm{Oxicu}^{\circledR}$ & IV \\
\hline Cloronitrilos & Clorotalonil $^{1}$ & 10 & Conan $^{\circledR} 720$ SC, Talonil ${ }^{\circledR} 75$ & IV \\
\hline $\begin{array}{l}\text { Ditio-carbamatos y } \\
\text { relativos }\end{array}$ & Mancozeb $^{1}$ & 22 & Manzate $^{\circledR} 200$ WP, Mancozeb ${ }^{\circledR}$ & IV \\
\hline \multirow[t]{2}{*}{ Ftalamidas } & Captán ${ }^{1}$ & 5 & Captan Ultra ${ }^{\circledR} 50 \mathrm{WP}$ & IV \\
\hline & Folpet $^{1}$ & 4 & Folpet $^{\circledR} 80$ WDG & IV \\
\hline
\end{tabular}

${ }^{1}$ Productos considerados altamente peligrosos (PAN, 2016).

de bacterias asociadas a pudriciones blandas en nopal verdura por Erwinia carotovora subs. carotovora (Colpos 2005), Pseudomonas sp. y Pectobacterium spp. (Torres-Bojórquez et al. 2016); sin embargo, en Tlalnepantla E. carotovora subs. carotovora ha mostrado incidencia baja (Colpos 2005), lo que posiblemente genera un número reducido de envases encontrados en esta categoría.

El resto de envases (69) se clasificaron como coadyuvantes, fertilizantes y nematicidas; ninguno de los insumos fitosanitarios clasificados cuenta con autorización para uso en el cultivo. Por su parte, se encontró como no vigente el producto con nombre

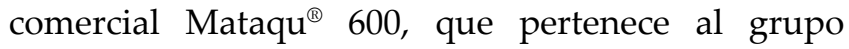
químico de los organofosforados, el resto estuvieron vigentes.

El uso de plaguicidas ha sido determinante para el control de plagas; sin embargo, estos agentes químicos empleados de forma inadecuada generan efectos nocivos a la salud (Amaya et al. 2008); adicionalmente el desecho de envases vacíos es un serio problema y representa un alto riesgo ambiental y de salud (García-Gutiérrez y Rodríguez-Meza 2012. Se requiere implementar prácticas como la técnica de triple lavado y traslado a almacenes temporales de envases (Siller et al. 2007), así como cumplimiento de las distintas disposiciones legales aplicables (SAGARPA 2000). Estas acciones en conjunto promoverán la reconversión a sistemas de bajos insumos, e incluso sustentables, para disminuir los riesgos a la salud y el impacto ambiental (Bernardino et al. 2016). Es recomendable igualmente la elaboración de estudios para detectar la posible existencia de contaminación por plaguicidas a fuentes de agua, trabajadores agrícolas y el producto final cosechado (Maki-Díaz et al. 2015).

\section{Conclusiones}

En el cultivo de nopal verdura, los envases de insumos fitosanitarios encontrados y clasificados en las parcelas son evidencia del peligro de contaminación química que representan. Una de las causas de este uso indiscriminado es la incidencia de plagas y enfermedades para las cuales no existen productos autorizados para uso en el cultivo que garanticen el control y que adviertan sobre la clasificación toxicológica, las precauciones durante el manejo del producto y las medidas para protección al ambiente, lo que pone en riesgo la salud del trabajador, el productor y el medio ambiente.

Reforzar programas regionales sobre el buen uso y manejo de agroquímicos a nivel regional por parte de autoridades estatales y federales sin lugar a dudas disminuirá el riesgo de contaminación de tipo químico a los trabajadores agrícolas y el ambiente.

\section{Agradecimientos}

Al Conacyt, por el apoyo económico para realizar estudios de posgrado a IIRB (No. 260454). A los productores de nopal verdura que facilitaron la inspección a sus unidades de producción. 


\section{LITERATURA CITADA}

Aguilar-Carpio C, Rangel-Estrada SE, Sánchez-Mendoza SM, Pérez-Ramírez A. 2016. Control químico de maleza en nopal verdura [Opuntia ficus-indica (L.) Miller]. Acta Agrícola y Pecuaria 2(1): 12-16.

Aldana ML, García MC, Rodríguez G, Silveira MI, Valenzuela AI. 2008. Determinación de insecticidas organofosforados en nopal fresco y deshidratado. Revista Fitotecnia Mexicana 31(2): 133-139.

Amaya EF, Roa AM, Camacho JE, Meneses S. 2008. Valoración de factores de riesgo asociados a los hábitos de manejo y exposición a organofosforados y carbamatos en habitantes y trabajadores de la vereda de Bateas del municipio de Tibacuy, Cundinamarca, Colombia. NOVA Publicación Científica en Ciencias Biomédicas. 6(10): 155-236.

Angeles-Núñez JG, Anaya-López JL, Arévalo-Galarza ML, Leyva-Ruelas G, Anaya S, Martínez-Martínez TO. 2014. Análisis de la calidad sanitaria de nopal verdura en Otumba, Estado de México. Revista Mexicana de Ciencias Agrícolas 5(1): 129-141.

Ayala-Escobar V, Yáñez-Morales MJ, Braun U, Groenewald JZ, Craus PW. 2006. Pseudocercospora opuntiae sp. nov., the causal organism of cactus leaf spot in Mexico. Fungal Diversity 21: 1-9.

Badii MH, Flores AE. 2001. Prickly pear cacti pests and their control in Mexico. Florida Entomologist 84(4): 503505. https://doi.org/10.2307/3496379

Bernardino H, Mariaca R, Nazar A, Álvarez JD, Torres A, Herrera C. 2016. Factores socioeconómicos y tecnológicos en el uso de agroquímicos en tres sistemas agrícolas en los altos de Chiapas, México. Interciencia 41(6): 382392.

Cano FK, Mendoza A. 2017. Nanoplaguicidas, ¿un verdadero avance para la agricultura? Revista Bio Ciencias 4(3): 164-178. https://doi.org/10.15741/231

Cerón-González C, Rodríguez-Leyva E, Lomelí-Flores JR, Hernández-Olmos CE, Peña-Martínez R, Mora-Aguilera G. 2012. Evaluación de insecticidas sintéticos sobre adultos de Metamasius spinolae (Coleoptera: Curculionidae) procedentes de Tlalnepantla, Morelos. Revista Mexicana de Ciencias Agrícolas 3: 217-229.

Chávez-Moreno CK, Tecante A, Casas A, Claps LE. 2011. Distribution and habitat in Mexico of Dactylopius Costas (Hemiptera: Dactylopiidae) and their cacti hosts (Cactaceae: Opuntioideae). Neotropical Entomology 40(1): 6271. https://doi.org/10.1590/S1519-566X2011000100009

[COFEPRIS] Comisión Federal para la Protección contra Riesgos Sanitarios 2017. Consulta de registros sanitarios de Plaguicidas y Nutrientes Vegetales [citado 2017, dic 15]. Disponible en:

http://189.254.115.250/Resoluciones/Consultas/ConWebRegPlaguicida.asp

[Colpos] Colegio de Postgraduados. 2005. Diagnóstico Fitosanitario del Nopal Verdura (Opuntia ficus-indica) en Tlalnepantla, Morelos. Documento de trabajo "Primera Reu- nión del Grupo Interdisciplinario de Investigación del Nopal". Colegio de Postgraduados. Montecillo, México. Cox C. 1998. Glyphosate (Roundup). Journal of Pesticide Reform 18(3): 3-17.

De Jesús AB, Aragón A, López JF, Rivera A, López V. 2016. Entomofauna asociada al nopal verdura (Opuntia ficusindica Miller) en San Andrés Cholula, Puebla, México. Southwestern Entomologist 41(1): 259-265. https://doi. org/10.3958/059.041.0123

[FAO] Organización de las Naciones Unidas para la Agricultura y la Alimentación. 2006. Código Internacional de Conducta para la Distribución y Utilización de Plaguicidas. Organización de las Naciones Unidas para la Agricultura y la Alimentación. Roma, Italia.

[FAO] Organización de las Naciones Unidas para la Agricultura y la Alimentación [internet]. 2008. Directrices sobre opciones de manejo de envases vacíos de plaguicidas [citado 2018, ene 13]. Disponible en: http://www. fao.org/fileadmin/templates/agphome/documents/ Pests_Pesticides/Code/Containers08SP.pdf

[FAO] Organización de las Naciones Unidas para la Agricultura y la Alimentación. 2015. Convenio de Rotterdam. Sobre el Procedimiento de Consentimiento Fundamentado previo aplicable a ciertos plaguicidas y productos químicos peligrosos objeto de comercio internacional. Roma, Italia.

[FRAC] Fungicide Resistance Action Committee [internet]. 2017. FRAC Code ListC 2017: Fungicides sorted by mode of action (including FRAC Code numbering) [citado 2018, ene 13]. Disponible en: http://www.frac.info/ docs/default-source/publications/frac-code-list/frac-code-list-2017-final.pdf?sfvrsn=fab94a9a_2

García-Gutiérrez C, Rodríguez-Meza GD. 2012. Sinaloa México. Problemática y riesgo ambiental por el uso de plaguicidas en Sinaloa. Ra Ximhai. 8(1):1-10.

Goldberg ED. 1995. Emerging problems in the coastal zone for the twenty-first century. Marine Pollution Bulletin 31: 152-158. https://doi.org/10.1016/0025-326X(95)00102-S

Gutiérrez-Ramírez A, Robles-Bermúdez A, Santillán-Ortega C, Ortíz-Catón M, Cambero-Campos OJ. 2013. Control biológico como herramienta sustentable en el manejo de plagas y su uso en el estado de Nayarit, México. Revista Bio Ciencias 2(3): 102-112.

Hernández-Sánchez E, Mora-Aguilera G, Tlapal B, Rodríguez-Leyva E, Alvarado D. 2014. Efecto de la intensidad inicial de enfermedad en la caracterización temporal y espacial de la mancha negra del nopal (Opuntia ficus-indica). Revista Mexicana de Fitopatología 32: 132-146.

Iwata H, Tanabe S, Sakai N, Nishimura A, Tatsukawa R. 1994. Geographical distribution of persistent organochlorines in air, water and sediments from Asia and Oceania, and their implications for global redistribution from lower latitudes. Environmental Pollution 85: 15-33.

[INAFED] Instituto para el Federalismo y el Desarrollo Municipal [internet]. 2010. Enciclopedia de los Municipios y Delegaciones de México. Morelos [citado 2017, 
dic 21]. Disponible en: http://inafed.gob.mx/work/enciclopedia/EMM17morelos/index.html

Lomeli-Flores JR, Rodríguez-Leyva E, Otero-Colina G, Mora-Aguilera G, Esquivel-Chávez F. 2008. Primer reporte de Tetranychus merganser (Acari: Tetranychidae) sobre Opuntia ficus indica L. en Tlalnepantla, Morelos. Entomología Mexicana 7: 21-25.

López-Martínez V, Pérez-De la O NB, Ramírez-Bustos I, Alia-Tejacal I, Jiménez-García D. 2016. Current and potential distribution of the cactus weevil, Cactophagus spinolae (Coleoptera: Curculionidae), in Mexico. The Coleopterist Bulletin 70(2): 327-334. https://doi.org/10.1649/0010-065X-70.2.327

Maki-Díaz G, Peña-Valdivia CB, García-Nava R, Arévalo-Galarza ML, Calderón-Zavala G, Anaya-Rosales S. 2015. Características físicas y químicas de nopal verdura (Opuntia ficus-indica) para exportación y consumo nacional. Agrociencia 49(1): 31-51.

Montoro Y, Moreno R, Gomero L, Reyes M. 2009. Características de uso de plaguicidas químicos y riesgos para la salud en agricultores de la sierra central de Perú. Revista Peruana de Medicina Experimental y Salud Pública 26(4): 466-472.

O'Connor PJ. 2000. The Safe and Effective Use of Pesticides. Oakland, USA.

[PAN] Pesticide Action Network International. 2016. PAN International List of Highly Hazardous Pesticides. PAN International. Hamburg, Germany.

Quezada-Salinas A, Sandoval-Islas JS, Alvarado-Rosales D, Cárdenas-Soriano E. 2006. Etiología de la mancha del nopal (Opuntia ficus-indica Mill) en Tlalnepantla, Morelos, México. Agrociencia 40(5): 641-653.

Reyes-Pérez N, Villanueva-Jiménez JA, Vargas-Mendoza MC, Cabrera-Mireles H, Otero-Colina G. 2013. Parámetros poblacionales de Tetranychus merganser Boudreaux (Acari: Tetranychidae) en papayo (Carica papaya L.) a diferentes temperaturas. Agrociencia 40(2): 641-653.

[SAGARPA] Secretaría de Agricultura, Ganadería y Desarrollo Rural. 2000. NOM-EM-034-FITO-2000. Norma Oficial Mexicana (con carácter de emergencia), requisitos y especificaciones para la aplicación y certificación de buenas prácticas agrícolas en los procesos de producción de frutas y hortalizas frescas. Diario Oficial de la Federación. México, D.F.

[SIAP] Servicio de Información Agroalimentaria y Pesquera. 2017. Atlas Agroalimentario [internet]. 2018. México [citado 2018, mar 16]. Disponible en: http://nube. siap.gob.mx/gobmx_publicaciones_siap/pag/2016/Atlas-Agroalimentario- 2016

Siller J, Báez M, Cháidez C, Gardea A. 2007. Producción y Manejo Poscosecha en la Industria Frutícola. In: Gardea AA, González GA, Higuera-Ciapara I, Cuamea F, editors. Buenas Prácticas en la Producción de Alimentos. Productos Pecuarios. Productos Agrícolas. Productos Acuícolas. Procesamiento de Alimentos. Editorial Trillas. p: 171-221.

Sparks T, Nauen R. 2015. IRAC: Mode of action classification and insecticide resistance management. Pesticide
Biochemistry and Physiology 121: 122-128. https://doi. org/10.1016/j.pestbp.2014.11.014.

Stintzing FC, Carle R. 2005. Cactus stems (Opuntia spp.) a review on their chemistry, technology, and uses. Molecular Nutrition Food Research 49(2): 175-194.

Torres-Bojórquez AI, Cervantes-Díaz L, Núñez-Ramírez F, Morales-Maza A, Samaniego-Gámez BY. 2016. Primer reporte de Pectobacterium spp. asociada a Opuntia ficus en Baja California, México. IDESIA 34(4): 69-71.

Vanegas-Rico JM, Lomeli-Flores JR, Rodríguez-Leyva E, Mora-Aguilera G, Valdez JM. 2010. Enemigos naturales de Dactylopius opuntiae (Cockerell) en Opuntia ficus-indica (L.) Miller en el centro de México. Acta Zoológica Mexicana (n.s.) 26(2): 415-433.

Vargas A, Flores A, Basaldua JF. 2008. Dinámica poblacional de las principales plagas de nopal Opuntia spp. en la zona semiárida de Querétaro. Revista Chapingo Zonas Áridas 7(1): 21-27.

[WHO] World Health Organization. 2010. The WHO Recommended Classification of Pesticides by Hazard. World Health Organization. Geneva, Switzerland.

Zaragoza-Bastida A, Valladares-Carranza B, Ortega-Santana C, Zamora-Espinosa J, Velázquez-Ordoñez V, Aparicio-Burgos J. 2016. Repercusiones del uso de organoclorados sobre el ambiente y salud pública. Abanico Veterinario 6(1): 43-55. 